\title{
CORROSION INHIBITION EFFECT OF ACIDIC EXTRACT OF BARK OF EUCALYPTUS GLOBULUS ON MILD STEEL
}

\author{
Dipak Kumar Gupta', Laxmi Awasthi ${ }^{2}$, Anju Kumari Das ${ }^{3}$, \\ Brahamdeo Yadav 4 , Anita Ghimire ${ }^{5}$, and Amar Prasad Yadav ${ }^{5 *}$ \\ ${ }^{1}$ Lecturer, Department of chemistry, Tri-Chandra Multiple Campus, Ghantaghar, \\ Kathmandu, TU. \\ ${ }^{2}$ Teacher, 'Ekata James College, Jorpati, Kathmandu. \\ ${ }^{3}$ Lecturer, Department of Chemistry, Amrit Campus, Lainchaur, Kathmandu, TU. \\ ${ }^{4}$ Lecturer, R.R.M. Campus, Janakpur, TU. \\ ${ }^{5}$ Professor, Central Department of Chemistry, Kirtipur, TU. \\ *Corresponding author: amar2y@yahoo.com
}

\begin{abstract}
The corrosion inhibition properties of the acidic extract of Eucalyptus globulus (EG) was investigated for mild steel (MS) using the weight loss method and open circuit potential (OCP) measurement. Corrosion inhibition of MS in $0.1 \mathrm{M} \mathrm{HCl}$ was studied in the absence and presence of various concentrations of the acidic extract of EG barks. The results showed an increase in corrosion inhibition with increasing concentration of the extract. The inhibition efficiency of $100 \%$ EG extract was approximately $98.0 \%$ after 24 hours immersion in the acidic solution. FTIR spectrum showed the presence of compounds containing oxygen and nitrogen functional groups responsible for forming barrier layers onto MS surface. Open circuit potential (OCP) measurements showed that the EG extract acts as a mixedtype inhibitor.
\end{abstract}

Keywords: corrosion inhibition - eucalyptus globules - green inhibitor - OCP weight loss

\section{INTRODUCTION}

Acid solutions are commonly used in several industrial processes. Hydrochloric and sulphuric acids are usually used for pickling, cleaning, descaling, and etching of metals, which also corrodes metal surface (Abdallah et al., 2018; Ngouné et al., 2019; Tezeghdenti et al., 2015). Mild steel in acid solution is widely used in various industrial processes, and corrosion 
occurs in this environment. The use of inhibitors is a useful method for corrosion protection, especially in acid media, to avoid dissolution and acid consumption (Arockiasamy et al., 2014; Moussaoui et al., 2016; Musa et al., 2009). Most of the well-known acid inhibitors are organic compounds containing nitrogen, sulphur, and oxygen in their functional groups with aromatic and heterocyclic rings (El-Etre et al., 2005; Halambek et al., 2010; Ngouné et al., 2019). These organic compounds get absorbed on the metal surface, block the active sites on the surface, forming a protective barrier, and reduce the corrosion rate (Verma et al., 2018). Toxicity and hazardous environmental nature of organic compounds, there is an increasing concern over non-toxic, environmentally acceptable, and inexpensive inhibitors (Mohd \& Ishak, 2015; Qiang et al., 2018; Saxena et al., 2018). Therefore, the study of sustainable corrosion inhibitors has attracted the attention of corrosion scientists. Most of the inhibitors obtained from natural products are biodegradable, non-toxic, eco-friendly, and cheaper (Halambek et al., 2010; Stiadi et al., 2020). It has encouraged the search for eco-friendly corrosion inhibitors as an alternative to replace inorganic and organic inhibitors to promote sustainable greenness to the environment.

Plant products are cheap, readily available, and renewable sources of materials. The extracts from their leaves, barks, seeds, fruits, and roots consist of mixtures of organic compounds containing nitrogen, sulphur, and oxygen atoms, and they have reported as effective inhibitors (El Hamdani et al., 2015; Rekkab et al., 2012). The extracts from leaves, barks, and oil of Eucalyptus globules (EG) have revealed that they are potential inhibitors (Rekkab et al., 2012). Tezeghdenti studied the corrosion inhibition effect of the methanolic extract of Eucalyptus globulus leaves in $1 \mathrm{M} \mathrm{H}_{2} \mathrm{SO}_{4}$ solution on carbon steel by weight loss measurements and different electrochemical methods. The inhibition efficiency of the methanolic extract of EG leaves in $1 \mathrm{M} \mathrm{H}_{2} \mathrm{SO}_{4}$ solution is better than the bark extracts of Eucalyptus camaldulens in $1 \mathrm{M} \mathrm{HCl}$ and the essential oil of Eucalyptus globulus (Myrtaceae) (Rekkab et al., 2012; Tezeghdenti et al., 2015). The literature reports that Eucalyptus globulus is a mixed type inhibitor and thermodynamically follows Langmuir adsorption isotherm. The present study reports on the corrosion inhibition properties of acidic bark extract of high altitude Eucalyptus globulus plant of Nepal. A hydrochloric acid extract of bark at different concentrations has been examined as a corrosion inhibitor. Nowadays, green inhibitors are considered as an attractive alternative. In this regard, many efforts have been made for a practical application of green inhibitors to have a better future, a safe environment, and a healthy life. The yield of these natural products and the corrosion inhibition efficacy of the plant extracts, vary 
extensively depending on the part of the plant (Okafor et al., 2008) and its location (Tezeghdenti et al., 2015). In this view, the objective of the present study is to investigate the corrosion inhibition of the EG barks extracts onto mild steel in $0.1 \mathrm{M} \mathrm{HCl}$ using the weight-loss method and open circuit potential (OCP) measurement.

\section{MATERIALS AND METHODS}

\section{Preparation of plant extract and inhibitor solution}

The fresh barks of Eucalyptus globulus were collected from Godavari, Lalitpur, Nepal (Lat: $27.596932^{\circ} \mathrm{N}$, Long: $85.380143^{\circ} \mathrm{E}$, and Elevation: $1342.00 \mathrm{~m}$ ). The barks were washed, cut, shade dried, and powdered. The extract was prepared by cold percolation in acid using 50 $\mathrm{g}$ of powder in $400 \mathrm{~mL}$ of $0.1 \mathrm{M} \mathrm{HCl}$ and allowed to stand for three days and then refluxed for about three hours. The mixture was filtered off, and the filtrate was diluted to $250 \mathrm{~mL}$ with $0.1 \mathrm{M} \mathrm{HCl}$, which was considered as $100 \%$ stock solution. From the stock solution, inhibitor solutions of 50, 40, 30,20 , and $10 \%$ were prepared in $0.1 \mathrm{M} \mathrm{HCl}$ solution by serial dilution.

\section{Preparation of mild steel coupon}

Mild steel (MS) sheet purchased from the local vendor of Kathmandu, Nepal, was mechanically cut into coupons of a dimension of $3 \mathrm{~cm}$ x $3 \mathrm{~cm}$ x $0.15 \mathrm{~cm}$. MS coupons were abraded with Silicon carbide (SiC) paper of \#100 to \#1500 grits. Abraded coupons were ultrasonicated in ethanol, and dried. These coupons were used for weight loss and open circuit potential (OCP) measurements.

\section{Characterization by FTIR}

The bark extract of Eucalyptus globulus was characterized by Fourier-transform infrared (FTIR) spectroscopy. A Perkin Elmer Spectrum GX FTIR was used to obtain infrared emission spectra with wavenumber ranging from 500 to $4000 \mathrm{~cm}^{-1}$ to identify the functional group present in the $100 \%$ extract.

\section{Weight loss method for corrosion test}

Weight loss measurements were performed on the mild steel (MS) coupons in $0.1 \mathrm{M} \mathrm{HCl}$ solution in the presence and absence of different concentrations of EG extract. Every MS coupon was weighed by an electronic analytical balance (Ohaus E1RR80), and then placed in the extract and acid solution $(50 \mathrm{~mL})$ for 9 days. After immersion, the surface of the coupon was washed with distilled water and dried. The coupons 
were weighed again to calculate the inhibition efficiency (IE\%) and the corrosion rate $(\mathrm{CR})$. The following relations determined the corrosion rate $(\mathrm{CR})$, surface coverage $(\theta)$, and inhibition efficiency (IE\%):

Corrosion Rate $(\mathrm{CR})=\frac{\mathrm{w}}{\mathrm{A} \times \mathrm{t} \times \mathrm{d}} \times 8.76 \times 10^{4}$

Where, $W$ is weight loss of the MS (g) after immersion time, $t$ (hours), A is the area of the MS $\left(\mathrm{cm}^{2}\right)$, and $\mathrm{d}$ is the density of the MS ( $\mathrm{g}$ $\left.\mathrm{cm}^{-3}\right)$.

Surface Coverage $(\theta)=\frac{\mathrm{W}_{1}-\mathrm{W}_{2}}{\mathrm{w}_{2}}$

Inhibition Efficiency $(I E) \%=\frac{\mathrm{W}_{1}-\mathrm{W}_{2}}{\mathrm{~W}_{2}} \times 100$

Where, $\mathrm{W}_{1}$ is the weight loss of the MS in the absence of inhibitor, and $\mathrm{W}_{2}$ is the weight loss of the MS in the presence of inhibitor.

\section{Open Circuit Potential}

The open circuit potential (OCP) or corrosion potential (Ecorr) measurement was carried out using a high impedance multimeter. A saturated calomel electrode was used as a reference electrode, and the MS coupon was used as a working electrode. The OCP was measured with different concentrations of inhibitor solutions in $0.1 \mathrm{M} \mathrm{HCl}$ after immersion of 24 hours for 25 days.

\section{RESULTS AND DISCUSSION}

\section{Effect of Concentration}

The weight loss results of MS, corrosion rate, surface coverage, and inhibition efficiency of various concentrations of EG extract for 24 hours immersion were calculated and given in table 1 . Table 1 clearly shows that the corrosion rate decreased with the increase in fractional surface coverage of MS. Figure 1a shows the variation of corrosion rate with the concentration of EG extracts. The corrosion rate was significantly reduced by $20 \%$ EG extract solution due to appreciable surface coverage of MS, thereby reducing the reaction with acid. Figure $1 \mathrm{~b}$ shows that the inhibition efficiency increases with an increase in the concentration of the EG extracts (Ajayi et al., 2014; Rukaiyat et al., 2018). The ability increased slightly after $30 \%$ inhibitor concentration due to almost complete surface coverage of MS. In acidic media, corrosion of metal is generally accompanied by the 
evolution of $\mathrm{H}_{2}$ gas and the dissolution of metal. The corrosion inhibitory action of the plant extracts against MS can be attributed to the component adsorption on the metal surface(Rekkab et al., 2012). This adsorption limits the dissolution of metal by blocking its corrosion sites and consequently decreasing weight loss(Abdallah et al., 2018; Hussin \& Kassim, 2011; Patel et al., 2018; Tezeghdenti et al., 2015). The inhibition efficiency of $100 \%$ concentration of EG extract after $24 \mathrm{~h}$ immersion is approximately $98 \%$.

Table 1: Corrosion rate, surface coverage and inhibition efficiency of the extract of Eucalyptus globulus at different concentrations

\begin{tabular}{|c|c|c|c|c|}
\hline $\begin{array}{l}\text { Concentration } \\
\text { of EG extract } \\
(\%)\end{array}$ & $\begin{array}{l}\text { Weight } \\
\text { Loss(g) }\end{array}$ & $\begin{array}{l}\text { Corrosion } \\
\text { Rate mm/ } \\
\text { year }\end{array}$ & $\begin{array}{l}\text { Surface } \\
\text { Coverage } \\
(\theta)\end{array}$ & $\begin{array}{l}\text { Inhibition } \\
\text { Efficiency } \%\end{array}$ \\
\hline Acid & 1.069 & 26.68 & & \\
\hline 10 & 0.6855 & 17.11 & 0.3587 & 35.87 \\
\hline 20 & 0.2003 & 5.044 & 0.8126 & 81.26 \\
\hline 30 & 0.1088 & 2.722 & 0.8982 & 89.82 \\
\hline 40 & 0.0366 & 0.9157 & 0.9657 & 96.57 \\
\hline 100 & 0.0228 & 0.5331 & 0.9786 & 97.86 \\
\hline
\end{tabular}

Source: From Experiment

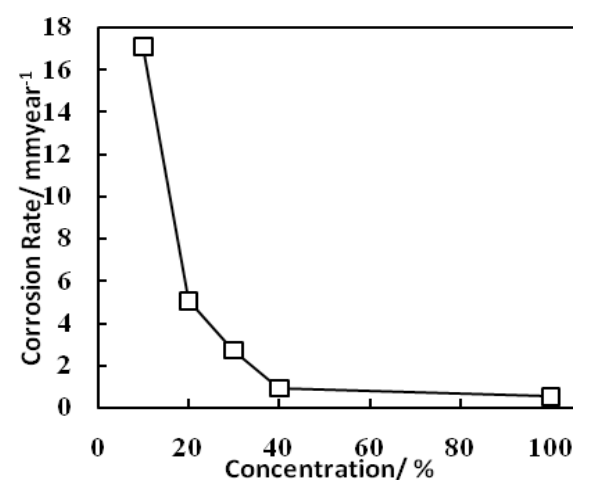

Figure 1a: Variation of corrosion rate with the concentration of $\mathrm{EG}$

\section{Open circuit potential (OCP)}

Figure 2 shows the effects of inhibitor concentrations on the change of OCP of the immersed MS coupon in EG extract solution with immersion 
time. The OCP shifts to the positive direction compared to the acid solution. In general, the time required to reach a stable OCP value depends on the concentration of the extract. A steady-state OCP value attains faster in a higher concentration compared to a lower concentration of the extract. The shift of OCP to a positive direction in the presence of the extract of EG indicating the formation of a passive film on the metal surface due to the adsorption of inhibitor molecules on the surface of the metal (Moussaoui et al., 2016). The OCP for $100 \%$ of $\mathrm{EG}$ extract is $-0.472 \mathrm{~V}$ after 25 days of immersion. However, the shift in OCP value compared to the acid only solution is less than $40 \mathrm{mV}$, which confirms that the extract of EG acts as a mixed type inhibitor.

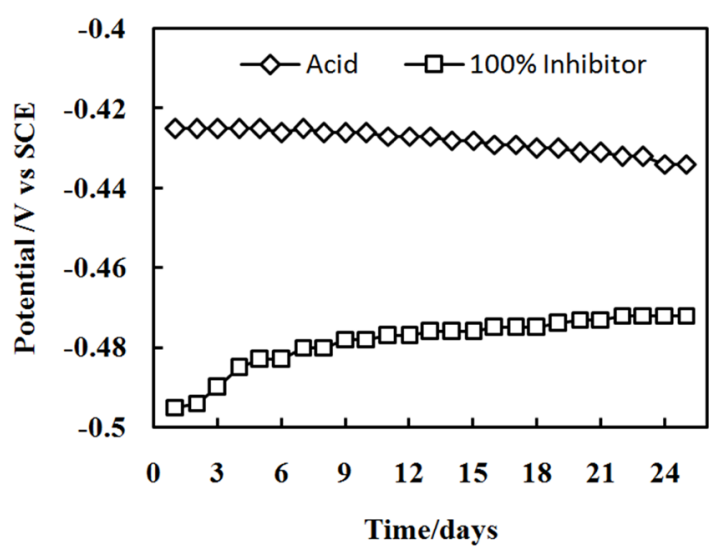

Figure 2: Variation of OCP against the time of immersion of mild steel in inhibitor and acid solution

\section{FTIR spectroscopic analysis}

The FTIR spectrum of the EG bark extracts is shown in Figure 3. Corrosion inhibitors are the potential compounds with a common functional group of hydroxyls $(-\mathrm{OH})$, carboxyl $(-\mathrm{COOH})$, carbonyl $(=\mathrm{CO}),-\mathrm{CO}-$, amine $(-\mathrm{N}-\mathrm{H})$ and other functional groups that have electrons pair. The infrared spectrum of EG extracts indicates the presence of $-\mathrm{OH}\left(3327 \mathrm{~cm}^{-1}\right)$, $\mathrm{C}-\mathrm{O}\left(2350 \mathrm{~cm}^{-1}\right), \mathrm{C}-\mathrm{N}\left(2164 \mathrm{~cm}^{-1}\right)$, and $\mathrm{C}=\mathrm{O}\left(1640 \mathrm{~cm}^{-1}\right)$ (Abboud et al., 2013). This IR spectrum shows the chemical component in EG, which acts as a corrosion inhibitor that can bond directly to form a stable complex by adsorption on the MS surface(Stiadi et al., 2020). 


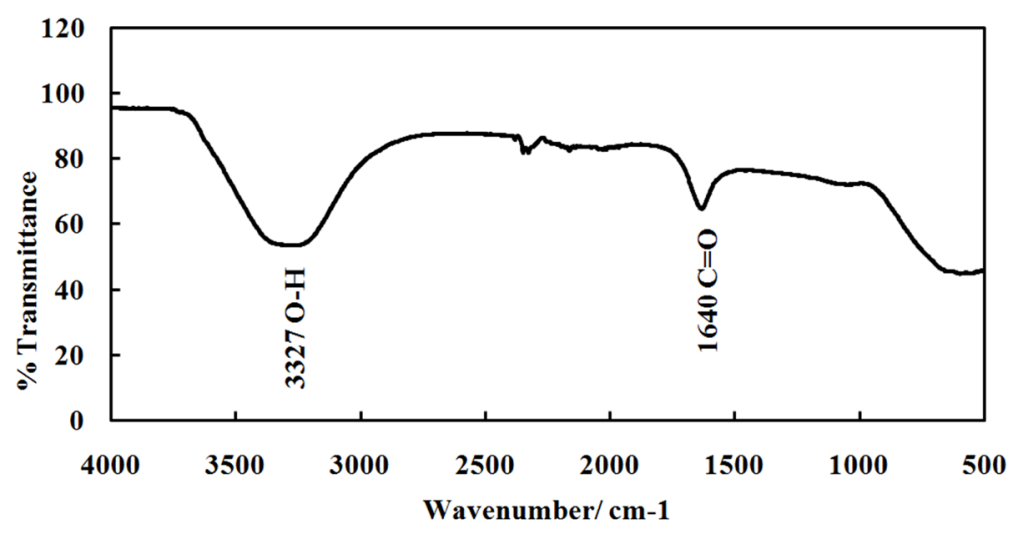

Figure 3: FTIR spectrum of EG extracts in $0.1 \mathrm{M} \mathrm{HCl}$

\section{Surface observation}

Figure 4 Shows digital photographs of inhibited and uninhibited MS coupons after 5 and 10 days corrosion in $0.1 \mathrm{M} \mathrm{HCl}$ and $\mathrm{EG}$ extract solution. The surface observation reveals that the metallic surface was highly damaged, rough, and corroded for uninhibited MS coupons (Fig. 4a and b). It is due to the free acid attack of MS surface in the absence of inhibitor. However, in the presence of 100\% EG extract (Fig. 4c and d), the MS surface became less damage and suggesting the formation of a protective film at MS surface.

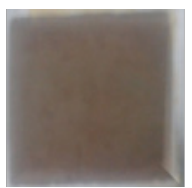

(a) MS dipped in $0.1 \mathrm{M} \mathrm{HCl}$ for 5 adys

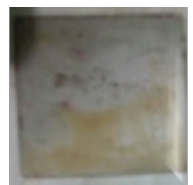

(c) MS dipped in $100 \%$ EG extract for 5 days

Figure 4: Digital photographs of MS coupons surface immersed $0.1 \mathrm{M} \mathrm{HCl}$ and $100 \%$ EG extracts

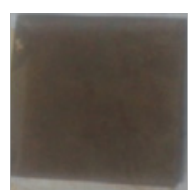

(b) MS dipped in $0.1 \mathrm{M} \mathrm{HCl}$ for 10 days

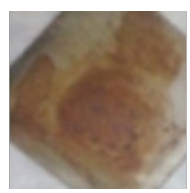

(d) MS dipped in 100\% EG extract for 10 days 


\section{CONCLUSION}

The study shows that Eucalyptus globulus bark is an effective ecofriendly corrosion inhibitor for mild steel (MS) in $0.1 \mathrm{M} \mathrm{HCl}$. The addition of bark extract drastically reduced the weight loss of the MS coupon due to the adsorption of compounds present in the acidic extract of EG bark. The corrosion rate is influenced by the concentration of the inhibitor and immersion time. The maximum inhibition efficiency of $100 \%$ EG extract is $97.87 \%$ for 24 hours of immersion in acidic solution. OCP measurement shows that the $E G$ extract act as a mixed type inhibitor for corrosion of MS in acidic solution. FTIR analysis suggests that the adsorption occurs due to the presence of functional group-containing oxygen and nitrogen, which forms the protective barrier film on MS surface.

\section{ACKNOWLEDGMENTS}

The authors would like to thank the Central Department of Chemistry, Tribhuvan University, and Tri- Chandra Multiple Campus, Ghantaghar, and Kathmandu to provide laboratory facilities to carry out this work.

\section{REFERENCES}

Abboud, Y., Chagraoui, A., Tanane, O., El Bouari, A., \& Hannache, H. (2013). Punica granatum leave extract as green corrosion inhibitor for mild steel in hydrochloric acid. MATEC Web of Conferences, 5, 04029. https://doi.org/10.1051/matecconf/20130504029

Abdallah, M., Altass, H. M., AL Jahdaly, B. A., \& Salem, M. M. (2018). Some natural aqueous extracts of plants as green inhibitor for carbon steel corrosion in $0.5 \mathrm{M}$ sulfuric acid. Green Chemistry Letters and Reviews, 11(3): 189-196. https://doi.org/10.1080/175 18253.2018.1458161

Ajayi, O. M., Odusote, J. K., \& Yahya, A. A. (2014). Inhibition of mild steel corrosion using Jatropha Curcas leaf extract. J. Electrochem. Sci. Eng., 4(2): 67-74. https://doi.org/doi: 10.5599/jese.2014.0046

Arockiasamy, P., Sheela, X. Q. R., Thenmozhi, G., Franco, M., Sahayaraj, J. W., \& Santhi, R. J. (2014). Evaluation of corrosion inhibition of mild steel in $1 \mathrm{M}$ hydrochloric acid solution by Mollugo cerviana. International Journal of Corrosion, 2014, 1-7. https:// doi.org/10.1155/2014/679192 
El Hamdani, N., Fdil, R., Tourabi, M., Jama, C., \& Bentiss, F. (2015). Alkaloids extract of Retama monosperma (L.) Boiss. seeds used as novel eco-friendly inhibitor for carbon steel corrosion in 1 $\mathrm{M} \mathrm{HCl}$ solution: Electrochemical and surface studies. Applied Surface Science, 35(7), 1294-1305. https://doi.org/10.1016/j. apsusc.2015.09.159

El-Etre,A. Y.,Abdallah, M., \& El-Tantawy,Z. E. (2005). Corrosion inhibition of some metals using lawsonia extract. Corrosion Science, 47(2): 385-395. https://doi.org/10.1016/j.corsci.2004.06.006

Halambek, J., Berković, K., \& Vorkapić-Furač, J. (2010). The influence of Lavandula angustifolia L. oil on corrosion of Al-3Mg alloy. Corrosion Science, 52(12): 3978-3983. https://doi.org/10.1016/j. corsci.2010.08.012

Hussin, M. H., \& Kassim, M. J. (2011). The corrosion inhibition and adsorption behavior of Uncaria gambir extract on mild steel in $1 \mathrm{M}$ HCl. Materials Chemistry and Physics, 125(3): 461-468. https:// doi.org/10.1016/j.matchemphys.2010.10.032

Mohd, N., \& Ishak, A. S. (2015). Thermodynamic study of corrosion inhibition of mild steel in corrosive medium by Piper nigrum extract. Indian Journal of Science and Technology, 8(17): 1-7. https://doi.org/10.17485/ijst/2015/v8i17/63478

Moussaoui, N., Zerouali, D., \& Bettahar, N. (2016). Inhibitive effect of date extract on the corrosion of carbon steel in acidic media. Journal of the Chilean Chemical Society, 61(3): 3018-3024. https://doi. org/10.4067/S0717-97072016000300002

Musa, A. Y., Kadhum, A. A. H., Mohamad, A. B., Daud, A. R., Sobri, M., Kamarudin, S. K., \& Muhamad, N. (2009). Stability of layer forming for corrosion inhibitor on mild steel surface under hydrodynamic conditions. Int. J. Electrochem. Sci., 4: 707-716.

Ngouné, B., Pengou, M., Nouteza, A. M., Nanseu-Njiki, C. P., \& Ngameni, E. (2019). Performances of alkaloid extract from rauvolfia macrophylla stapf toward corrosion inhibition of C38 steel in acidic media. ACS Omega, 4(5): 9081-9091. https://doi.org/10.1021/ acsomega.9b01076

Okafor, P. C., Ikpi, M. E., Uwah, I. E., Ebenso, E. E., Ekpe, U. J., \& Umoren, S. A. (2008). Inhibitory action of Phyllanthus amarus extracts on the corrosion of mild steel in acidic media. Corrosion Science, 50(8): 2310-2317. https://doi.org/10.1016/j.corsci.2008.05.009 
Patel, A. N., Dave, P. Y., \& Malik, G. M. (2018). Corrosion inhibition study of citrus aurantium bark (lemon) powder as green inhibitor for mild steel in sulphuric acid. PRAJÑ $\bar{A}$ - Journal of Pure and Applied Sciences, 26: 53 - 61.

Qiang, Y., Zhang, S., Tan, B., \& Chen, S. (2018). Evaluation of ginkgo leaf extract as an eco-friendly corrosion inhibitor of X70 steel in $\mathrm{HCl}$ solution. Corrosion Science, 133: 6-16. https://doi.org/10.1016/j. corsci.2018.01.008

Rekkab, S., Zarrok, H., Salghi, R., Zarrouk, A., Bazzi, L., Hammouti, B., Kabouche, Z., Touzani, R., \& Zougagh, M. (2012). Green corrosion inhibitor from essential oil of eucalyptus globulus (myrtaceae) for C38 steel in sulfuric acid solution. J. Mater. Environ. Sci., 3(4): 613-627.

Rukaiyat, M. S., Abubakar, G. S., \& Fatima, M. K. (2018). Corrosion inhibition of mild steel using alkaloids and tannins extracts of Jatropha curcas in acidic media. Bayero Journal of Pure and Applied Sciences, 10(1): 311-317. https://doi.org/10.4314/bajopas. v10i1.62S

Saxena, A., Prasad, D., Haldhar, R., Singh, G., \& Kumar, A. (2018). Use of Saraca ashoka extract as green corrosion inhibitor for mild steel in $0.5 \mathrm{M} \mathrm{H}_{2} \mathrm{SO}_{4}$. Journal of Molecular Liquids, 258: 89-97. https:// doi.org/10.1016/j.molliq.2018.02.104

Stiadi, Y., Rahmayeni, Rahmawati, L., Efdi, M., Aziz, H., \& Emriadi. (2020). Mangifera odorata griff seed extract as corrosion inhibitor of mild steel in hydrochloric acid medium. Rasayan Journal of Chemistry, 13(01): 230-239. https://doi.org/10.31788/RJC.2020.1315325

Tezeghdenti, M., Dhouibi, L., \& Etteyeb, N. (2015). Corrosion inhibition of carbon steel in $1 \mathrm{M}$ sulphuric acid solution by extract of Eucalyptus globulus leaves cultivated in Tunisia arid zones. Journal of Bioand Tribo-Corrosion, 1(16): 1-9. https://doi.org/10.1007/s40735015-0016-x

Verma, C., Quraishi, M. A., Ebenso, E. E., \& Bahadur, I. (2018). A green and sustainable approach for mild steel acidic corrosion inhibition using leaves extract: experimental and DFT studies. Journal of Bio- and Tribo-Corrosion, 4(33): 1-12. https://doi.org/10.1007/ s40735-018-0150-3 